\title{
Segurança jurídica e ato de concessão de aposentadoria em regime próprio: uma análise do Recurso Extraordinário no $636.553 /$ RS
}

Legal security and act of granting retirement in own regime: an analysis of Extraordinary Appeal n ${ }^{\circ}$ 636.553/RS

Francisco Clayton Brito Júnior ${ }^{1}$

\section{RESUMO}

Este artigo objetiva analisar o julgamento do Recurso Extraordinário $\mathrm{n}^{\mathrm{o}}$ 636.553 proferido pelo Supremo Tribunal Federal e demonstrar alguns conceitos e consequências empreendidos de tal análise. Realiza-se um estudo acerca da competência constitucional dos Tribunais de Contas no que concerne à apreciação, para fins de registro, da legalidade da aposentadoria em regime próprio. Analisará o princípio da segurança jurídica no quadro dos direitos fundamentais como um fator de estabilização das relações sociais e como um princípio basilar do Estado Democrático de Direito. Sucede-se um estudo reflexivo, explicativo e descritivo do caso concreto da Suprema Corte do Poder Judiciário brasileiro, que se desenvolverá por meio de pesquisas bibliográficas relacionadas à temática. Conclui-se que os Tribunais de Contas possuem função social relevante e evidente na apreciação da legalidade da aposentadoria em regime próprio, bem como conclui-se a segurança jurídica como um direito fundamental relevante e um fator de estabilização das relações jurídicas e sociais.

Palavras-Chave: STF. Tribunal de Contas. Aposentadoria. Segurança Jurídica. Direitos Fundamentais.

1 Mestrando em Direito pelo Centro Universitário Christus (Unichristus). Especialista em Direito e Processo do Trabalho pela Universidade Anhanguera (Uniderp). Especialista em Controle Externo pela Universidade Estadual Vale do Acaraú (UVA). Bacharel em Direito pelo Centro Universitário Farias Brito (UNIFB). Consultor Técnico no Tribunal de Contas do Estado do Ceará. E-mail: claytonbritojr@hotmail.com 


\section{ABSTRACT}

This paper aims to analyze the judgment of Extraordinary Appeal No. 636,553 issued by the Supreme Federal Court and demonstrate some concepts and consequences undertaken from such analysis. A study is carried out on the constitutional competence of the Courts of Accounts with regard to the assessment, for purposes of registration, of the legality of retirement under the proper regime. It will analyze the principle of legal certainty within the framework of fundamental rights as a factor in stabilizing social relations and as a basic principle of the Democratic Rule of Law. A reflective, explanatory and descriptive study of the specific case of the Supreme Court of the Brazilian Judiciary is carried out, developing through bibliographic research related to the theme. It is concluded that the Courts of Accounts have a relevant and evident social function in assessing the legality of retirement under their own regime, as well as concluding legal certainty as a relevant fundamental right and a factor in stabilizing legal and social relations.

Keywords: STF. Audit Office. Retirement. Legal Security. Fundamental Rights.

Recebido: $10-08-2020$

Aprovado: 17-10-2020

\section{INTRODUÇÃO}

O que se pretende com o presente trabalho é analisar o julgamento do RE 636.553/RS pelo Supremo Tribunal Federal e demonstrar alguns conceitos e consequências empreendidos de tal análise, explicitando de forma breve a Teoria dos Direitos Fundamentais, o princípio da segurança jurídica e a atuação dos Tribunais de Contas na concessão de aposentadoria.

Desse modo, objetiva-se examinar, à luz da Teoria dos Direitos Fundamentais, o princípio da segurança jurídica, o ato concessório de 
aposentadoria e a atuação das Cortes de Contas nesta seara.

Diante da relevância do julgamento do RE 636.553/RS, da mudança parcial de entendimento do plenário do STF a respeito do tema e da repercussão prática nas Cortes de Contas, surgiu a necessidade de realizar a presente pesquisa.

De início, destaca-se a atuação dos Tribunais de Contas, com referências a sua competência constitucional e sua natureza de órgão auxiliar do Poder Legislativo, no que se refere ao exercício controle externo, com uma explanação acerca da atuação das Cortes de Contas na apreciação da legalidade do ato concessivo de aposentadoria. Demonstra-se, com base na doutrina e jurisprudência, a natureza jurídica do ato de concessão inicial de aposentadoria.

Num segundo momento, discorre-se acerca do princípio da segurança jurídica no quadro dos direitos fundamentais, trazendo à baila uma breve explanação sobre a Teoria dos Direitos Fundamentais do jurista alemão Robert Alexy e demonstrando sua nítida relevância para o estudo, aplicação do Direito em si e para a análise de caso concreto.

Por fim, faz-se uma análise acurada do julgamento do RE 636.553/ RS pelo Supremo Tribunal Federal, utilizando-se a doutrina de Robert Alexy, Virgílio Afonso e Jane Reis, no que concerne especialmente ao instituto da ponderação e outras teorias.

A metodologia que será utilizada neste trabalho caracterizar-se-á como um estudo reflexivo, explicativo e descritivo do caso concreto da Suprema Corte do Poder Judiciário brasileiro, desenvolvendo-se por meio de pesquisas eminentemente bibliográficas relacionadas à temática.

\section{A ATUAÇÃO DOS TRIBUNAIS DE CONTAS NA CONCES- SÃO DE APOSENTADORIA EM REGIME PRÓPRIO}

Nos Estados democráticos, em regra, o Poder Legislativo conta 
com o auxílio de um órgão especializado na fiscalização da atuação dos poderes públicos. No Estado democrático brasileiro não é diferente, pois a Constituição Federal atribui ao Tribunal de Contas relevantes atribuições para cumprir esse mister como órgão fiscalizador da atuação dos poderes públicos.

Essas atribuições elencadas nesse dispositivo aplicam-se, pelo princípio da simetria constitucional (art. 75 da CF), a todos os Tribunais de Contas do Brasil, de modo que não podem inserir no âmbito de sua competência atribuições não mencionadas no art. 71 da CF.

Cumpre destacar que o Tribunal de Contas é órgão auxiliar do Poder Legislativo no exercício do controle externo, porém não o integra e não é subordinado a ele. Dessarte, muito embora essa atribuição seja de auxílio, reveste-se de alta significação.

Nesse prisma, o Supremo Tribunal Federal decidiu:

A posição constitucional dos Tribunais de Contas - Órgãos investidos de autonomia jurídica - Inexistência de qualquer vínculo de subordinação institucional ao Poder Legislativo - Atribuições do Tribunal de Contas que traduzem direta emanação da própria Constituição da República. Os Tribunais de Contas ostentam posição eminente na estrutura constitucional brasileira, não se achando subordinados, por qualquer vínculo de ordem hierárquica, ao Poder Legislativo, de que não são órgãos delegatórios nem organismos de mero assessoramento técnico. A competência institucional dos Tribunais de Contas não deriva, por isso mesmo, de delegação dos órgãos do Poder Legislativo, mas traduz emanação que resulta, primariamente, da própria constituição da República. Doutrina. Precedentes (STF. ADI 4190. Ministro Relator: Celso de Mello. J. 10.03.2010. DJE 11.06.2010).

Outrossim, conforme destacou o ex-Ministro do STF Ayres Britto (2001, p. 4), ressaltando a participação obrigatória do Tribunal de Contas no exercício do controle externo, "é inconcebível o exercício da função 
estatal do controle externo sem o necessário concurso ou o contributo obrigatório dos Tribunais de Contas".

Desse modo, os Tribunais de Contas, muito embora não possuam o poder legiferante típico do Legislativo e nem o poder judicante (no sentido de jurisdição) típico do Judiciário, tornaram-se instrumentos de inquestionável relevância, na atualidade, no contexto do controle e na defesa de postulados que informam a própria organização da Administração Pública.

As competências das Cortes de Contas encontram-se expressamente consagradas nos incisos do art. 71 da Constituição Federal e podem ser divididas em fiscalizatória, judicante, sancionaria, consultiva, informativa e corretiva. Esta classificação se dá segundo a atuação da Corte de Contas e decorre da interpretação do supramencionado dispositivo constitucional. Dentre as competências fiscalizadoras, destaca-se a prevista no inciso III do art. 71 da CF, verbis:

III - apreciar, para fins de registro, a legalidade dos atos de admissão de pessoal, a qualquer título, na administração direta e indireta, incluídas as fundações instituídas e mantidas pelo Poder Público, excetuadas as nomeações para cargo de provimento em comissão, bem como a das concessões de aposentadorias, reformas e pensões, ressalvadas as melhorias posteriores que não alterem o fundamento legal do ato concessório.

Compreende-se nesta competência do Tribunal de Contas da União (TCU), dentre outras, a apreciação da legalidade das concessões de aposentadorias, reformas e pensões que, por simetria, aplica-se aos demais Tribunais de Contas.

No que concerne ao instituto da aposentadoria, um dos principais benefícios da previdência social, direito social consagrado no art. $6^{\circ} \mathrm{da} C F$ e, portanto, direito fundamental de segunda dimensão, impende registrar sua definição. 
Segundo Carvalho Filho (2010, p. 753):

\begin{abstract}
Aposentadoria é o direito, garantido pela Constituição, ao servidor público, de perceber determinada remuneração na inatividade diante da ocorrência de certos fatos jurídicos previamente estabelecidos.

A aposentadoria é um fato jurídico-administrativo que precisa se formalizar através de um ato administrativo da autoridade competente. Esse ato sujeita-se à apreciação do Tribunal de Contas, a quem incumbe verificar a sua legalidade diante da efetiva consumação do suporte fático do benefício (art. 71, III, $\mathrm{CF})$.
\end{abstract}

A aposentadoria é, pois, de modo inquestionável, um direito fundamental garantido constitucionalmente ao servidor público, de receber remuneração na inatividade ante a ocorrência de fatos jurídicos previamente estabelecidos.

No entanto, paira divergência na doutrina a despeito da natureza jurídica do ato administrativo de concessão de aposentadoria, que para alguns é ato composto e para outros ato complexo, mas há quem entenda ser ato simples.

$\mathrm{O}$ ato administrativo simples, diferentemente dos atos composto e complexo, depende da manifestação de vontade de um único órgão para produzir efeitos no mundo jurídico. É considerando essa classificação de ato jurídico que o Ministro Fachin no RE 636.553/RS entende que o ato de aposentadoria é, em verdade, um ato administrativo simples, segundo o qual se consuma e perfectibiliza tão somente com a manifestação da vontade autônoma da administração pública de concessão da aposentadoria. O Ministro entende que a manifestação do Tribunal de Contas sobre o ato concessório da aposentadoria não constitui manifestação de vontade autônoma para fins de aperfeiçoar o ato, mas sim um controle da legalidade do ato $a$ posteriori.

$\mathrm{O}$ ato administrativo composto depende da manifestação de vontade 
de dois ou mais órgãos, no qual há uma única manifestação de vontade principal e autônoma e outra ou outras meramente acessória e instrumental.

Por sua vez, o ato complexo também depende da manifestação de vontade de dois ou mais órgãos, porém o que os diferencia é que, neste caso, há duas vontades principais e autônomas com conteúdo próprio em cada uma das manifestações.

Destaque-se que, embora mais de um órgão expresse sua vontade, em verdade, um único ato será produzido após o processo de formação da vontade final da Administração. Para Carvalho Filho (2010, p. 144), quanto aos efeitos desses atos, "temos que os atos que traduzem a vontade final da Administração só podem ser considerados perfeitos e acabados quando se consuma a última das vontades constitutivas de seu ciclo".

Nessa senda, não obstante a reafirmação pelo STF, por maioria de votos, no $R E n^{\circ} 636.553$, a despeito da natureza jurídica do ato administrativo concessivo da aposentadoria ser ato complexo, a doutrina de Justen Filho defende ser ato composto:

Nesse ponto, altera-se o entendimento anteriormente adotado e se reconhece a procedência do raciocínio de Carvalho Filho, no sentido de que a aposentadoria não é um ato complexo. Nas edições anteriores, seguia-se o posicionamento tradicional, no sentido de que a aposentadoria se aperfeiçoava mediante a edição de decreto da autoridade mais elevada do Poder conjugada com a aprovação com o Tribunal de Contas. No entanto e como procedimento aponta Carvalho Filho, a aposentadoria se aperfeiçoa com a mera emissão do decreto. $\mathrm{O}$ ato de aprovação do Tribunal de Contas envolve apenas controle a posteriori sobre a regularidade do ato (JUSTEN FILHO, 2012, p. 945).

Por outro lado, acompanhando o posicionamento reafirmado no STF, a doutrina majoritária assevera que o ato concessivo de aposentadoria consiste num fato administrativo que se formaliza através de um ato administrativo complexo, ou seja, que depende de duas manifestações de vontade autônomas, uma da autoridade competente a qual o servidor está 
vinculado e a outra do Tribunal de Contas, a quem cabe o controle de sua legalidade, conforme explicitou Marinela (2012).

Convém anotar que a aposentadoria e seu respectivo registro, diante dos diversos requisitos (tempo de contribuição, idade, sexo etc.) exigidos constitucionalmente para sua concessão, por si só, trazem consigo alta complexidade na análise da matéria. A nosso ver, a decisão do Tribunal de Contas, quando realiza o controle de legalidade e decide pelo registro do ato inicial de aposentadoria, constitui uma vontade principal e autônoma. Logo, essa manifestação de vontade por parte do Tribunal de Contas, juntamente com o ato inicial de aposentadoria emitido pela administração pública, caracterizam o ato de aposentadoria como um ato administrativo complexo, pois somente a partir do julgamento pelo registro do ato pela Corte de Contas pode-se afirmar que a aposentadoria se encontra aperfeiçoada e consumada. Nesse sentido, a jurisprudência atual do STF reafirmada no RE 636.553/RS.

Desta feita, com essa competência prevista no art. 71, III, da CF, os Tribunais de Contas apreciam a legalidade dos atos concessivos de aposentadorias. Em verificando a conformidade do ato com os ditames legais e constitucionais disciplinadores da matéria, a Corte de Contas registra o ato, momento em que se perfectibiliza e se consuma definitivamente o ato de aposentadoria (ressalvadas as melhorias posteriores que não alterem o fundamento legal do ato concessório).

Caso contrário, sendo constatada a existência de irregularidades no ato concessivo de aposentadoria ${ }^{2}$, a Corte de Contas nega registro e julga ilegal referido ato, momento em que encaminha os autos ao órgão ou entidade de origem, recomendando a adoção de providências devidas para suprir as irregularidades detectadas.

Observe-se que, uma vez formalizado o registro da legalidade do

2 "A aposentadoria é ato administrativo sujeito ao controle do Tribunal de Contas, que detém competência constitucional para examinar a legalidade do ato e recusar o registro quando lhe faltar base legal" (RE $\mathrm{n}^{\circ}$ 197.227/ ES, Pleno. Relator: Min. Ilmar Galvão. Julg. 22.10.1996. Dj, 7 fev. 1997). 
ato de aposentadoria pelo Tribunal de Contas, momento da consumação do ato, fica vedada a administração pública de promover alterações (ressalvadas as melhorias posteriores que não alterem o fundamento legal do ato concessório), sem submeter a igual procedimento.

Em linhas gerais, o procedimento de concessão de aposentadoria do servidor público se inicia com o setor pessoal do órgão ou entidade ao qual o servidor está vinculado, quando é analisado se o servidor preenche os requisitos legais. Caso preencha tais requisitos, concede o benefício por meio do chamado ato inicial de aposentadoria, que é precário e inacabado, segundo jurisprudência atual do STF. Empós, haverá um controle de legalidade realizado pelo Tribunal de Contas. Somente após esse controle, a aposentadoria poderá ser considerada definitivamente concedida e consumada.

Cumpre destacar, por fim, que os Tribunais de Contas examinam as aposentadorias concedidas a servidores estatutários ocupantes de cargos efetivos e aos militares. Não lhes cabe, todavia, apreciar, para fins de registro, as aposentadorias dos servidores beneficiários do regime geral da previdência social.

\section{O PRINCÍPIO DA SEGURANÇA JURÍDICA NO QUADRO DOS DIREITOS FUNDAMENTAIS}

Nessa esteira de compreensão da atuação dos Tribunais de Contas no ato concessivo de aposentadoria do servidor público estatutário, é imperioso discorrer a respeito da segurança jurídica no quadro dos direitos fundamentais.

É oportuno iniciar com uma frase proferida pelo Ministro Marco Aurélio Mello, que resumiu a palestra organizada pela Escola Superior da Magistratura do Amazonas (ESMAM): "a segurança jurídica é um direito fundamental do cidadão" (informação verbal) $)^{3}$.

3 Palestra proferida por Marco Aurélio Mello no auditório Ataliba David Antônio na Sede do Tribunal de Justiça do Amazonas, em Manaus, em 10 de maio de 2013. 
Acrescentou que a segurança jurídica constitui um princípio fundamental da Constituição Federal e que "o artigo quinto faz alusão à segurança jurídica quando dá garantias ao cidadão à educação, à liberdade, ao trabalho" (informação verbal) ${ }^{4}$.

Assim, entende-se a segurança jurídica como direito fundamental do cidadão e um princípio constitucional. Não obstante estar implícita na Constituição, a mesma se revela no artigo quinto quando estabelece garantias aos indivíduos.

Com efeito, destacou que "em sociedade, não podemos viver sendo surpreendidos, não podemos viver aos solavancos" (informação verbal) 5 . Isso reflete a principal característica ou objetivo do princípio da segurança jurídica, qual seja, estabilização das relações jurídicas. Nesse sentido, deve-se evitar a surpresa aos jurisdicionados. Incumbe, portanto, à segurança jurídica estar presente no Estado Democrático como um fator de estabilidade exigido pela ordem normativa, como um fator desestimulador da insegurança e incerteza jurídica.

O princípio da segurança jurídica, que tem como face subjetiva a proteção à confiança ou confiança legítima, deve ser visto como garantia fundamental assegurada de forma implícita na Constituição Federal.

$\mathrm{O}$ princípio em análise tem como institutos norteadores o direito adquirido, o ato jurídico perfeito e a coisa julgada (art. $5^{\circ}$, XXXVI da CF). Tais institutos, uma vez aperfeiçoados e concretizados, tornam-se imutáveis. Quanto à garantia constitucional da coisa julgada, deve ser vista como algo imutável, de forma a assegurar a eficácia das decisões proferidas pelo Poder Judiciário. Destaque-se que o postulado da segurança jurídica exerce um papel imprescindível na garantia da coisa julgada.

Esses institutos norteadores relacionam-se a um dos pontos principais da segurança jurídica: a irretroatividade das normas jurídicas. Assim, "a lei é editada não para apanhar atos e fatos pretéritos, mas para atos

\begin{tabular}{ll}
\hline 4 & Ibid. \\
5 & Ibid.
\end{tabular}


e fatos futuros. Sendo assim, a primeira condição da segurança jurídica como um princípio básico da Constituição Federal é a irretroatividade da lei" (informação verbal) ${ }^{6}$.

Para Canotilho, há diferença entre princípio da segurança jurídica e da proteção à confiança, além de que reforça a necessidade de segurança jurídica para o homem conduzir de forma autônoma sua vida:

o homem necessita de segurança jurídica para conduzir, planificar e conformar autônoma e responsavelmente a sua vida. Por isso, desde cedo se consideravam os princípios da segurança jurídica e proteção à confiança como elementos constitutivos do Estado de direito. Estes dois princípios - segurança jurídica e proteção à confiança - andam estreitamente associados, a ponto de alguns autores considerarem o princípio da proteção da confiança como um subprincípio ou como uma dimensão específica da segurança jurídica. Em geral, considera-se que a segurança jurídica está conexionada com elementos objetivos da ordem jurídica - garantia de estabilidade jurídica, segurança de orientação e realização do direito - enquanto a proteção da confiança se prende mais com as componentes subjetivas da segurança, designadamente a calculabilidade e previsibilidade dos indivíduos em relação aos efeitos jurídicos dos actos (CANOTILHO, 2000, p. 256).

Versando sobre o tema, José Afonso da Silva aduz:

A temática deste número liga-se à sucessão de leis no tempo e à necessidade de assegurar o valor da segurança jurídica, especialmente no que tange à estabilidade dos direitos subjetivos. A segurança jurídica consiste no "conjunto de condições que tornam possível às pessoas o conhecimento antecipado e reflexivo das consequências diretas de seus atos e de seus fatos à luz da liberdade reconhecida". Uma importante condição da segurança jurídica está na relativa certeza de que os indivíduos têm de que as relações realizadas sob o império de uma norma devem perdurar ainda quando tal norma seja substituída (SILVA, 2000, p. 435).

$6 \quad$ Ibid.

Rev. Controle, Fortaleza, v. 19, n.1, p. 393-422, jan./jun. 2021. 
É inegável a relevância do princípio da segurança jurídica para fins de atribuir estabilidade e certeza nas relações jurídicas e sociais.

Para o Ministro do STF, Gilmar Mendes (2020, p. 14), "a segurança jurídica, como subprincípio do Estado de Direito, assume valor ímpar no sistema jurídico, cabendo-lhe papel diferenciado na própria ideia de justiça material"'.

Sendo um valor ímpar no sistema jurídico e uma garantia insuprimível, o postulado da segurança jurídica encontra guarida na legislação infraconstitucional. Dentre outros dispositivos legais, o art. $2^{\circ}$ da Lei $n^{o}$ 9.784/99 inclui a segurança jurídica como princípio de observância obrigatória pela administração pública e o art. 24 da Lei de Introdução às Normas do Direito Brasileiro (LINDB) regula a revisão de atos na esfera administrativa, controladora e judicial.

Nesse contexto, denota-se a segurança jurídica como um princípio fundamental e norteador do Estado Democrático de Direito que não só está relacionado aos direitos fundamentais como é ele próprio um direito fundamental. Esse princípio assegura certeza e evita surpresas às pessoas em suas relações jurídicas e sociais, conforme destacado em princípio. Assim sendo, discorrer acerca dos direitos fundamentais se faz necessário.

Para uma melhor digressão acerca dos direitos fundamentais, imperioso lembrar a Teoria dos Direitos Fundamentais, contributo de Robert Alexy para o desenvolvimento da temática, com uma breve análise acerca das principais características.

Segundo Alexy (2008), os direitos fundamentais são essencialmente os direitos humanos transformados em direito positivo, uma vez que os direitos humanos necessitam serem institucionalizados. Logo, não haveria direito humano à vida se não houvesse direito humano à existência de um Estado que implementasse esse direito.

Os direitos fundamentais possuem relação intrínseca com os direitos humanos, pois surgiram como forma de proporcionar o desenvol-

$\overline{7 \quad \text { STF. RE } 636.553 / \text { RS. }}$ 
vimento da pessoa humana e de garantir o respeito a sua dignidade, no movimento político e cultural que originou a Declaração dos Direitos do Homem e do Cidadão de 1789.

Apesar de consagrados de forma sistemática no texto constitucional, do art. $5^{\circ}$ ao 17 , os direitos fundamentais não se limitam a estes. Estão distribuídos por toda a constituição e ordenamento jurídico, inclusive tratados internacionais de direitos humanos ratificados pelo Brasil.

Destacando a mudança de posição do Estado na relação com os direitos fundamentais, o Ministro Gilmar Mendes (2011) apresenta a interpretação da Corte Constitucional alemã sob nova dimensão dos direitos fundamentais, segundo a qual o Estado evolui da condição de "adversário" para uma posição de guardião desses direitos. Nessa senda, o Estado tem o dever de agir para garantir a realização e concretização dos direitos fundamentais.

Dentre as principais características da Teoria dos Direitos Fundamentais do jurista alemão Robert Alexy (2008), encontram-se a diferenciação entre as regras e princípios, o instituto da ponderação e sopesamento, a colisão de direitos fundamentais, a máxima da proporcionalidade e a teoria da argumentação.

Diferentemente de Ronald Dworkin ${ }^{8}$ (2002), para quem o sistema jurídico compõe-se de regras, princípios e políticas, Robert Alexy (2008) entende que o sistema jurídico compõe-se de duas espécies normativas, quais sejam, as regras e os princípios.

As normas de direitos fundamentais possuem caráter duplo (regra/princípio). A despeito da distinção entre essas normas jurídicas, Alexy assevera:

Essa distinção é a base da teoria da fundamentação no âmbito dos direitos fundamentais e uma chave para a solução de problemas centrais da dogmática dos direitos fundamentais. Sem ela não

8 Segundo Dworkin (2002), Herbert Hart compreende o sistema jurídico compondo-se somente de regras (primárias e secundárias). Entretanto, em seu pós-escrito, Hart indica, em verdade, que seu conceito de regra (que seria melhor chamada genericamente de norma) abrange tanto o que Dworkin chama de regra quanto o que ele chama de princípio. 
pode haver nem uma teoria adequada sobre as restrições a direitos fundamentais, nem uma doutrina satisfatória sobre colisões, nem uma teoria suficiente sobre o papel dos direitos fundamentais no sistema jurídico. [...] A distinção entre regras e princípios constitui, além disso, a estrutura de uma teoria normativo-material dos direitos fundamentais [...]. Nesse sentido, a distinção entre regras e princípios é uma das colunas-mestras do edifício da teoria dos direitos fundamentais (ALEXY, 2008, p. 85).

A teoria dos direitos fundamentais tem como um de seus pilares a teoria dos princípios, ou seja, a distinção entre regras e princípios.

Cumpre salientar que estas normas possuem estruturas lógicas diferentes, de modo que o critério qualitativo é o que as distingue e não o critério quantitativo ou de grau (ALEXY, 2008).

As regras expressam razões definitivas enquanto normas que garantem direitos e impõem deveres definitivos. Essas normas impõem uma ordenação certa e limitada, bem assim não buscam atingir, no futuro, um estado de coisas.

As regras são sempre satisfeitas ou não satisfeitas e, caso sejam válidas, devem ser aplicadas por inteiro, nem mais, nem menos, sem flexibilização ou ponderação. Neste azo, "regras contêm, portanto, determinações no âmbito daquilo que é fática e juridicamente possível. Isso significa que a distinção entre regras e princípios é uma distinção qualitativa, e não uma distinção de grau" (ALEXY, 2008, p. 91).

Por sua vez, os princípios caracterizam-se como normas jurídicas que devem ser aplicadas na maior medida do possível, ante as possibilidades fática e jurídicas existentes. Enquanto mandamentos de otimização, os princípios podem ser satisfeitos em graus variados, revelando-se mais ou menos amplos, a depender das circunstâncias do caso concreto.

Esse mandamento de otimização, característico dos princípios, relaciona-se necessariamente à máxima da proporcionalidade e à técnica do sopesamento, em razão da possibilidade de colisão com outros princípios 
ou direitos fundamentais no caso concreto. Desse modo, ao estabelecerem razões que podem ser afastadas, num caso concreto, os princípios são sempre razões prima facie.

Em suma, as diferenças estruturais entre regras e princípios são: quanto ao tipo de mandamento, regras são mandamentos a serem cumpridos na medida exata e princípios mandamentos de otimização; quanto a natureza de suas razões, regras são razões definitivas ${ }^{9}$ e princípios razões prima facie; quanto ao cumprimento, regras "nem mais, nem menos" e princípios "mais ou menos"; e quanto a dimensão onde ocorrem os conflitos normativos, regras na dimensão da validade e os princípios na dimensão do peso.

Dentre outros atributos, a diferença entre regras e princípios constitui-se numa das principais características da Teoria dos Direitos Fundamentais de Robert Alexy. Outros aspectos dessa teoria serão analisados no próximo tópico. Saliente-se que essa teoria é essencial para a compreensão e análise da decisão do Supremo Tribunal Federal (RE 636.553).

\section{ANÁLISE DO CASO CONCRETO - RE 636.553/RS - STF}

No caso julgado, o Tribunal de Contas da União (TCU), em 4 de novembro de 2003 (Acórdão 2.699/2003 - $1^{\text {a }}$ Câmara), analisou uma aposentadoria do servidor público João Darci Rodrigues de Oliveira, constatando irregularidades, razão pela qual declarou a ilegalidade do benefício.

Verificou-se que o processo administrativo de deferimento inicial do benefício ingressou no TCU em 18/07/1996 e que o julgamento pela ilegalidade do ato de aposentadoria ocorreu há mais sete anos.

Constatou-se que o servidor público foi notificado da decisão do TCU, sendo oportunizada a interposição de recurso administrativo, em observância aos princípios do contraditório e ampla defesa, no entanto,

9 Princípios são sempre razões prima facie e regras são, se não houver o estabelecimento de alguma exceção, razões definitivas (ALEXY, 2008). 
o recurso interposto pelo servidor foi rejeitado nos termos do Acórdão 1675/04 - $1^{\text {a }}$ Câmara.

O caso chegou à Justiça Federal e, por decisão do Tribunal Regional da $4^{\text {a }}$ Região (TRF-4), impediu-se a administração pública de cassar esse ato inicial de aposentadoria, mesmo diante da verificação de irregularidades, em virtude de ter sido ultrapassado o prazo decadencial previsto no art. 54 da Lei n ${ }^{\circ}$ 9.784/99.

Em sede de recurso extraordinário, a União contesta a decisão do TRF-4 e alega que há violação ao art. $5^{\circ}, \mathrm{XXXV}$ e LV, ao art. 37, caput, ao art. 71 e ao art. 74 da Carta Magna, argumentado que o ato de aposentadoria somente se aperfeiçoa após a análise da legalidade por parte do TCU, não se submetendo, dessa forma, ao prazo decadencial previsto no art. 54 da Lei ${ }^{\circ}$ 9.784/99, tampouco à exigência de observância ao contraditório e ampla defesa.

No julgamento do recurso extraordinário, com repercussão geral reconhecida (tema 445), por maioria de votos, o STF negou provimento ao recurso da União, manifestando-se no sentido de que: o art. 54 da Lei $\mathrm{n}^{\circ}$ 9.784/99 não se aplica diretamente à apreciação da legalidade do ato de aposentadoria pelo Tribunal de Contas; é necessária a observância do prazo de 5 anos (art. $1^{\circ}$ do Decreto $n^{\circ} 20.910 / 1932$ ), a contar do ingresso dos autos à Corte de Contas, em atenção aos princípios da segurança jurídica e da confiança legítima; o ato concessório de aposentadoria é um ato administrativo complexo.

Ressaltou-se que transcorreram mais de cinco anos entre a chegada do processo administrativo ao TCU e a decisão proferida pela Corte de Contas e quase vinte e quatro anos até a data do julgamento do recurso extraordinário (19 de fevereiro de 2020), o que atraiu a incidência do princípio da segurança jurídica.

Cumpre registrar que a decisão judicial em análise não transitou em julgado. Insatisfeita com o julgamento, a União interpôs embargos de declaração em 18 de junho de 2020, ainda não julgado.

Uma vez explicitada a situação fática do caso concreto, passa-se 
a analisar a decisão do Plenário do STF na apreciação do Recurso Extraordinário $n^{\circ}$ 636.553/RS, cujo julgamento ocorreu em 19/02/2020. De início, transcreve-se a ementa:

Recurso extraordinário. Repercussão geral. 2. Aposentadoria. Ato complexo. Necessária a conjugação das vontades do órgão de origem e do Tribunal de Contas. Inaplicabilidade do art. 54 da Lei 9.784/1999 antes da perfectibilização do ato de aposentadoria, reforma ou pensão. Manutenção da jurisprudência quanto a este ponto. 3. Princípios da segurança jurídica e da confiança legítima. Necessidade da estabilização das relações jurídicas. Fixação do prazo de 5 anos para que o TCU proceda ao registro dos atos de concessão inicial de aposentadoria, reforma ou pensão, após o qual se considerarão definitivamente registrados. 4 . Termo inicial do prazo. Chegada do processo ao Tribunal de Contas. 5. Discussão acerca do contraditório e da ampla defesa prejudicada. 6. TESE: "Em atenção aos princípios da segurança jurídica e da confiança legítima, os Tribunais de Contas estão sujeitos ao prazo de 5 anos para o julgamento da legalidade do ato de concessão inicial de aposentadoria, reforma ou pensão, a contar da chegada do processo à respectiva Corte de Contas". 7. Caso concreto. Ato inicial da concessão de aposentadoria ocorrido em 1995. Chegada do processo ao TCU em 1996. Negativa do registro pela Corte de Contas em 2003. Transcurso de mais de 5 anos. 8 . Negado provimento ao recurso (STF. Plenário. RE 636553/RS, Rel. Min. Gilmar Mendes. Julg. 19.02.2020. DJe 26.05.2020. Repercussão geral - Tema 445. Acórdão p. 2, grifo nosso). ${ }^{10}$

Ante a formação da tese supramencionada, o STF manteve sua jurisprudência nos seguintes pontos: os atos de concessão de aposentadoria são complexos (e não simples como defendeu Fachin em voto vencido); o art. 54 da Lei $n^{\circ}$ 9.784/99 (prazo decadencial) não se aplica ao ato de concessão inicial de aposentadoria, só se aplicando após o registro da le-

10 Participaram do julgamento deste recurso extraordinário os Ministros Dias Toffoli (Presidente), Marco Aurélio, Gilmar Mendes, Ricardo Lewandowski, Rosa Weber, Roberto Barroso, Edson Fachin e Alexandre de Moraes. Não participou, justificadamente, deste julgamento, o Ministro Luiz Fux. Ausentes, justificadamente, a Ministra Cármen Lúcia e o Ministro Celso de Mello. 
galidade do ato pelo Tribunal de Contas; e a súmula vinculante 3 continua em vigor e não precisa conceder contraditório e ampla defesa nesse tipo de processo.

Entretanto, com essa tese, prestigiando os princípios da segurança jurídica e da confiança legítima, a jurisprudência do STF evoluiu ao definir que após decorrido o prazo de 5 anos (art. $1^{\circ}$ do Decreto $n^{\circ} 20.910 / 1932$ ), contados do ingresso do processo administrativo no Tribunal de Contas, haverá um registro tácito do ato de aposentadoria, onde tal ato será considerado definitivamente registrado.

Insta salientar que o art. 71, III, da Constituição e a legislação não estabelecem prazo específico ao Tribunal de Contas para exercer a competência delineada nesse dispositivo. Era a jurisprudência do $\mathrm{STF}^{11}$ que determinava ser concedido o contraditório e a ampla defesa ao jurisdicionado após o prazo de 5 anos, sem, no entanto, haver qualquer prazo limite para o Tribunal de Contas apreciar a legalidade do ato concessivo inicial de aposentadoria.

Convém mencionar trecho da decisão em análise, onde o relator frisa a necessidade de ponderação entre o princípio da segurança jurídica e o princípio da legalidade dos atos da Administração Pública. Verbis:

Por meio desse distinguishing, é possível determinar qual entendimento jurisprudencial será aplicado ao caso concreto. Nas hipóteses em que existe ato jurídico perfeito - isto é, já julgado e devidamente registrado pelo Tribunal de Contas - que concede aposentadoria ou pensão, entende esta Corte que a sua posterior anulação pelo próprio Tribunal de Contas, após decorrido um extenso lapso temporal e criada situação de estabilidade jurídica para o administrado, deve ser precedida de processo administrativo com plena participação dos interessados, assegurados o contraditório e a ampla defesa.

Nos demais casos, considera-se que o julgamento pelo Tribunal de Contas da legalidade dos atos administrativos concessivos de aposentadorias ou pensões realiza-se sem a participação dos interessados e não se submete a prazo decadencial.

11 STF. MS n ${ }^{\circ}$ 24.781, Plenário. Rel. Min. Ellen Gracie, Rel. p/ acórdão Min. Gilmar Mendes. Julg. 2.3.2011, DJe, 8 jun. 2011. 
Entretanto, é preciso observar esse entendimento à luz da ponderação entre o princípio da segurança jurídica, como "subprincípio" do Estado de Direito, e o princípio da legalidade dos atos da Administração Pública, levando em conta as garantias fundamentais da ampla defesa e do contraditório e sua incidência no âmbito dos processos administrativos (STF. Plenário. RE 636553/RS, Rel. Min. Gilmar Mendes. Julg. 19.02.2020. DJe 26.05.2020. Repercussão geral - Tema 445. Acórdão p. 13, grifo nosso).

O Ministro Fachin, que na conclusão acompanhou o relator e divergiu em alguns pontos do voto do relator, também destacou o embate entre legalidade e segurança jurídica:

No entanto, a legalidade não pode ser entendida apenas de forma estrita e dissociada de sua adjetivação constitucional, sendo, em verdade, legalidade constitucional. Portanto, a legalidade deve estar diretamente conectada aos princípios reitores do Estado Democrático Constitucional de Direito.

Não é por outra razão, que a própria Constituição da República privilegia a segurança jurídica, prevendo a prescritibilidade como regra e a imprescritibilidade como exceção. Nessa toada, mesmo atos que, em princípio, não se afigurariam hígidos à luz da estrita legalidade, recebem, em obediência à segurança jurídica, o manto cobertor da estabilidade (STF. Plenário. RE 636553/RS, Rel. Min. Gilmar Mendes. Julg. 19.02.2020. DJe 26.05.2020. Repercussão geral - Tema 445. Acórdão p. 45-46).

No caso, o STF, sem apresentar maior destaque, estabeleceu uma ponderação entre os princípios supostamente incidentes na espécie, quais sejam, segurança jurídica e legalidade. Infere-se, portanto, a colisão desses princípios quando da apreciação do caso concreto.

E, nesse ponto, a teoria dos princípios de Robert Alexy contribui com o instituto do sopesamento para a solução dos conflitos entre princípios, de modo que se identifica no caso concreto qual dos interesses, abstratamente no mesmo nível, tem maior peso.

Nesse contexto, há a necessidade de estabelecimento de relações 
condicionadas de precedência ou prevalência entre os princípios colidentes, onde ao final se constrói determinações definitivas de dever ser, assim como nas regras (ALEXY, 2008).

Nesse caso concreto, deu-se prevalência à segurança jurídica sem invalidar o outro princípio colidente, originando o dever ser definitivo, qual seja:

Em atenção aos princípios da segurança jurídica e da confiança legítima, os Tribunais de Contas estão sujeitos ao prazo de 5 anos para o julgamento da legalidade do ato de concessão inicial de aposentadoria, reforma ou pensão, a contar da chegada do processo à respectiva Corte de Contas (STF. Plenário. RE 636553/RS, Rel. Min. Gilmar Mendes. Julg. 19.02.2020. DJe 26.05.2020. Repercussão geral - Tema 445. Acórdão p. 83).

Como se percebe, a colisão dos princípios e a prevalência de um em face do outro quando da ponderação no caso concreto, não invalidou o princípio da legalidade (art. 71, III da CF), pois o Tribunal de Contas continua com sua competência para apreciar, para fins de registro, os atos de aposentadoria. Apenas, no entanto, deu-se prevalência ao princípio da segurança jurídica, estabelecendo um prazo razoável para o exercício do seu múnus público, cinco anos, cujo termo inicial é a entrada do ato inicial de aposentadoria na Corte de Contas.

Em se tratando da proporcionalidade e sopesamento, para Alexy (2008), a "máxima da proporcionalidade", que seria a proporcionalidade em sentido estrito, significa a exigência do sopesamento. Na colisão entre princípios, o sopesamento, unindo-se aos subprincípios da adequação e necessidade, desaguam numa decisão proporcional. Essa máxima da proporcionalidade decorre de os princípios serem mandamentos de otimização.

Para Silva (2009, p. 178-179), na "regra da proporcionalidade" é importante a distinção entre sopesamento e proporcionalidade em sentido estrito, pois "em alguns casos se deve recorrer ao sopesamento; em 
outros, à regra da proporcionalidade". A proporcionalidade em sentido estrito deve ser utilizada quando existe um normativo infraconstitucional restringindo um direito fundamental. Já o sopesamento, mais raramente utilizado, incide em casos que ainda não há regra infraconstitucional que discipline a colisão.

Segundo Jane Reis Gonçalves Pereira (2018), o juízo da ponderação é pautado pelo princípio da proporcionalidade, cuja estrutura argumentativa determina o modo que o judiciário deve implementar o sopesamento e fundamentar a solução final.

Imperioso destacar que o instituto da ponderação segundo Pereira (2018) é método complementar aos métodos tradicionais de interpretação constitucional, de modo que ponderação e métodos tradicionais não são antagônicos.

Impende transcrever a definição de ponderação de Pereira:

A ponderação é a técnica interpretativa destinada a identificar e formular a norma jurídica aplicável ao caso concreto que, nas últimas décadas, veio a assumir grande destaque na metodologia das Cortes Constitucionais, sendo empregada como metódica alternativa aos esquemas formalistas. O vocábulo ponderação tem sido usado para designar, de forma genérica, as diversas operações hermenêuticas consistentes em sopesar bens, valores, interesses, normas ou argumentos. Em sentido estrito, a ponderação pode ser definida, de forma esquemática, como a técnica de decisão pela qual o operador jurídico contrapesa, a partir de um juízo dialético, os bens e interesses juridicamente protegidos que se mostrem inconciliáveis no caso concreto, visando a determinar qual deles possui maior peso e, assim, identificar a norma jurídica abstrata que há de prevalecer como fundamento da decisão adotada (2018, p. 262).

Infere-se desta definição e da análise da colisão existente no caso concreto em apreço, a nosso ver, que de fato houve o juízo de ponderação nos termos como propõe a autora, tendo em vista que comandos opostos incidiram numa mesma situação fática e, por isso, não podem ser efetiva- 
dos ao mesmo tempo por apresentarem consequências divergentes.

Destaque-se que os métodos de interpretação constitucional não estão previstos expressamente e decorrem da forma de entender o ordenamento jurídico, os direitos fundamentais e a relação entre as funções judicial e legislativa. Com essa ideia, Pereira (2018, p. 263) apresenta contribuição relevante:

Essas três formas de interpretar a Constituição são orientadas por fatores extrassistemáticos, vale dizer, não é o texto constitucional que determina o método de interpretação a ser empregado. A escolha metodológica, como se sabe, é densamente condicionada: i) pela concepção que se tenha a respeito da relação entre o juiz e o texto escrito, ou seja, pelo conceito de interpretação judicial empregado; ii) pela tese que se adote sobre o papel do Judiciário no quadro da divisão funcional do poder; e iii) pela filosofia jurídica que subjaz à percepção do intérprete (PEREIRA, 2018, p. 263, grifo nosso).

Nesse sentido, a despeito das escolhas metodológicas e interpretação nos termos apresentados pela autora, no presente caso concreto há três pontos de destaque. Ressalte-se que para a autora não há distinção entre interpretação e aplicação do direito.

No primeiro ponto, o Ministro Fachin entendeu o ato de aposentadoria como um ato simples, ao passo que a maioria o entendeu como ato complexo, mantendo neste ponto a jurisprudência. Tal divergência de interpretação, de certo modo, retrata as palavras supramencionadas da autora, para quem a metodologia é densamente condicionada pela filosofia jurídica que subjaz à percepção do intérprete.

Um segundo ponto que merece destaque é que o Pretório Excelso decidiu ser inaplicável o art. 54 da Lei no 9.784/99 ao ato de concessão inicial de aposentadoria, até mesmo em decorrência da decisão da maioria no sentido de considerá-lo um ato complexo. Utilizou-se da analogia prevista no art. $4^{\circ}$ da LINDB para aplicar a este caso concreto o prazo razoável de 5 
anos, previsto no art. $1^{\circ}$ do Decreto $\mathrm{n}^{\mathrm{o}} 20.910 / 1932^{12}$, para que o Tribunal de Contas aprecie a legalidade do ato de aposentadoria. $\mathrm{O}$ relator aduz: "tendo em vista o princípio da isonomia, parece-me que o mais correto seria a aplicação por analogia do Decreto 20.910/1932”. E acrescenta: “Ora, se o administrado tem o prazo de 5 anos para buscar qualquer direito contra a Fazenda Pública, também podemos considerar que o Poder Público, no exercício do controle externo, teria o mesmo prazo para rever eventual ato administrativo favorável" ao jurisdicionado. Referida interpretação, de certo modo, retrata o posicionamento da autora, para quem a metodologia pode ser densamente condicionada pela concepção que se tenha a respeito da relação entre o juiz e o texto escrito, ou seja, pelo conceito de interpretação judicial empregado.

Um terceiro ponto que merece destaque é o voto divergente do Ministro Marco Aurélio, cujo excerto transcreve-se:

"Pronto! Estão todos aposentados!" E as situações precárias criadas a partir do órgão de origem se tornam, em um passe de mágica, definitivas.

Tem-se que pensar no Brasil. Tem-se que pensar na segurança jurídica. Tem-se que pensar na prevalência do Direito positivo. Tem-se, diria mesmo, que amar - e o verbo foi afastado do Código Civil - um pouco mais a Lei das leis, que é a Constituição Federal.

$\mathrm{O}$ sistema não fecha. $\mathrm{O}$ sistema não fecha a partir do momento em que se diz que o ato originário é um ato precário e efêmero, e conclui-se, agora, que considerada a passagem do tempo, sem que exista lei dispondo que os Tribunais de Contas do País têm prazo para apreciar aposentadorias e pensões a eles enviadas, $o$ ato se transmuda em definitivo. [...]

A lei que versa a decadência, o que pressupõe? Ato jurídico perfeito e acabado. E, então, a Administração Pública tem cinco anos para revê-lo. No processo de aposentadoria, no processo alusivo à pensão, não se tem, presente o ato primeiro, que é o

$12 \quad$ Art. $1^{\circ}$ As dívidas passivas da União, dos Estados e dos Municípios, bem assim todo e qualquer direito ou ação contra a Fazenda federal, estadual ou municipal, seja qual for a sua natureza, prescrevem em cinco anos contados da data do ato ou fato do qual se originarem. 
do órgão de origem do servidor, ato jurídico perfeito e acabado. Como fazer incidir esse prazo e dizer que a Administração Pública decaiu da possibilidade de proceder, em fase que compõe a higidez do ato primeiro, ao exame de registro? Como, sem lei a prever, com sanção, tempo para o Tribunal de Contas se pronunciar? Assentar-se que tem prazo para fazê-lo e que, não o fazendo, decai do direito de cumprir a Constituição Federal - direito-dever - de proceder à análise, sob o ângulo da legalidade, é passo, Presidente, demasiadamente largo.

E não é o fato de o Supremo não ter acima dele órgão para rever as decisões que profira que o levará a fechar a Constituição Federal, a colocar em segundo plano o arcabouço normativo tal como elaborado pelo Congresso Nacional. Ao contrário, essa circunstância cobra dos integrantes do Tribunal responsabilidade maior, e já se disse que se está decidindo com repercussão ímpar no Brasil, no Brasil continental.

[...] E são muitos, Presidente, são milhares os processos que aguardam o crivo do órgão de controle há mais de cinco anos. $\mathrm{O}$ ato é complexo e não se pode afastar o exame visando o registro, sacramentando-se, ante a passagem dos cinco anos, o que estabelecido pelo órgão de origem do servidor? Onde está, no arcabouço normativo pátrio, que, passados cinco anos, os órgãos de controle decaem do direito de examinar a situação jurídica? Sem o registro, o ato continua precário; o ato continua submetido a uma condição resolutiva, que pode se operar mesmo após cinco anos, ou seja, à revelada pela glosa dos cálculos efetuados, sabe lá como, pelo órgão de origem.

É passo, Presidente, demasiadamente largo que, sem ser legalista ao extremo, não consigo dar, porque não cabe substituir o Congresso Nacional. Estar-se-á como que aprovando ato normativo, estabelecendo prazo, estabelecendo sanção que não atende ao interesse público, ao interesse da sociedade, drástica, além de desconhecer-se que as Cortes de Conta estão sobrecarregadas. [...]. Provejo o recurso (STF. Plenário. RE 636553/RS, Rel. Min. Gilmar Mendes. Julg. 19.02.2020. DJe 26.05.2020. Repercussão geral - Tema 445. Acórdão p. 76-77, grifo nosso).

Neste azo, lembrando as palavras mencionadas alhures de Pereira (2018), para quem a metodologia de interpretação é densamente condi- 
cionada, o voto acima transcrito, de certo modo, é condicionado pela tese que se adote sobre o papel do Judiciário no quadro da divisão funcional do poder. Isto porque no voto defende-se o exercício da função legiferante pelo Legislativo e a não invasão do Judiciário a essa função.

Impende salientar, embora de modo sintético, para fins de análise do julgado em apreço, acerca das teorias que versam sobre as restrições aos direitos fundamentais e a respeito dos suportes fáticos amplo e restrito dos direitos fundamentais.

A partir do problema da colisão entre direitos fundamentais e da necessária restrição deles em algumas situações, surgem as teorias interna e externa para explicar as restrições a direitos dessa natureza. Para a teoria interna, há um único objeto, o direito e seus limites imanentes. Por sua vez, para a teoria externa, há dois objetos, o direito em si e as suas restrições.

Sobre a teoria interna, Silva (2009, p. 128) assevera: “o processo de definição dos limites de cada direito é algo interno a ele. É sobretudo nessa perspectiva que se pode falar em limites imanentes". Nesse sentido, só há um objeto, o direito com seus limites imanentes. Continua o autor: “A fixação desses limites, por ser um processo interno, não é definida nem influenciada por aspectos externos, sobretudo não por colisões com outros direitos".

Na teoria externa há dois objetos, "o direito em si, e, destacadas dele suas restrições" (SILVA, 2009, p. 138). Ademais, essas restrições externas aos direitos fundamentais não influenciam no conteúdo do direito, podendo apenas, no caso concreto, restringir seu exercício. Para Silva, há uma relação de proximidade entre a teoria externa e a teoria dos princípios:

A relação entre a teoria externa e a teoria dos princípios é a mais estreita possível. De forma muito simples, a teoria dos princípios sustenta que, em geral, direitos fundamentais são garantidos por uma norma que consagra um direito prima facie. Como visto no capítulo anterior, o suporte fático dessa norma- 
que tem a estrutura de princípio - é o mais amplo possível. Isso implica, entre outras coisas, que a colisão com outras normas pode exigir uma restrição à realização desse princípio. Essas normas constituem, portanto, as restrições ao direito fundamental garantido pelo princípio em questão (SILVA, 2009, p. 139).

Quanto ao suporte fático, sua definição abrange o âmbito de proteção e a intervenção não fundamentada constitucionalmente. No suporte fático restrito tem-se uma exclusão apriorística de certas condutas ou formas de exercício, as quais poderiam ser inseridas no âmbito de proteção da norma. Por outro lado, no suporte fático amplo há uma interpretação ampliada do âmbito de proteção do direito, no sentido de interpretar do modo mais amplo possível o direito fundamental. No entanto, esta forma ampla de proteção ocorre somente prima facie e não de forma definitiva (SILVA, 2009).

Ante as definições das teorias ora apresentadas e considerando especialmente o julgamento proferido no RE 636.553/RS, bem como levando em consideração, dentre outros aspectos, a colisão entre princípios no caso concreto e a formação do direito definitivo ao final do julgamento, tem-se que, embora não se tenha detectado critérios em relação a adoção de uma determinada teoria para fundamentar as restrições aos direitos fundamentais, neste caso, adotou-se, mesmo que de modo implícito, a teoria externa com suporte fático amplo.

\section{CONSIDERAÇÕES FINAIS}

Deste estudo extraem-se conclusões sobre aspectos importantes enfatizados a partir de uma análise acurada do julgamento do Recurso Extraordinário $n^{\circ}$ 636.553/RS do Supremo Tribunal Federal, que apreciou em repercussão geral o tema da aposentadoria no que diz respeito à apreciação da legalidade do ato inicial de aposentadoria por parte do Tribunal de Contas. 
O Tribunal de Contas, não obstante seja órgão auxiliar do Poder Legislativo, conforme preceitua a Constituição Federal, não o integra e não se subordina a ele. Logo, são órgãos que não fazem parte da estrutura de qualquer dos três poderes e que possuem autonomia institucional e independência para cumprimento do múnus público outorgado pela Lei maior. As Cortes de Contas, portanto, possuem atuação essencial na sociedade brasileira.

O ato de concessão inicial de aposentadoria emitido pelo órgão de origem ao qual o servidor público é vinculado passa pelo crivo do Tribunal de Contas no que concerne à apreciação da legalidade, que, caso esteja em conformidade com os ditames legais relativos à espécie, registra-o. Caso contrário, nega-se o registro. Concluiu-se, portanto, que se trata de ato administrativo complexo, uma vez que para se completar, aperfeiçoar e consumar, necessita da vontade autônoma de dois órgãos. Assim, enquanto não registrado pelo Tribunal de Contas, o ato inicial de aposentadoria é precário e inacabado. Somente após o registro desse ato é que se pode afirmar que o ato está definitivamente consumado e aperfeiçoado, ou seja, que a aposentadoria está definitivamente concedida. Há, no entanto, divergência doutrinária, conforme demonstrado.

Por sua vez, instituto importante na estabilização das relações jurídicas e sociais, a segurança jurídica constitui-se num princípio basilar do Estado Democrático de Direito. Ademais, está intrinsecamente relacionado aos direitos fundamentais.

Observa-se o quão importante é a Teoria dos Direitos Fundamentais do jurista alemão Robert Alexy para o estudo e aplicação do Direito em si e para a análise de caso concreto, onde merece destaque a diferenciação das normas jurídicas com estruturas de regras e de princípios, bem como ressalta-se a lei da colisão entre princípios e o instituto da ponderação e sopesamento.

Vale lembrar as teorias apresentadas por Virgílio Afonso, onde pode-se identificar que no caso analisado, mesmo que implicitamente, perce- 
beu-se a aplicação da teoria externa com suporte fático amplo.

Identificou-se, com a aplicação prática dos métodos interpretativos e complementares de interpretação e aplicação do direito de Jane Reis, a influência de tais métodos na compreensão do Direito e na aplicação correta e coerente do Direito ao caso concreto.

Verificou-se, no caso concreto, o quão oportuno é o estudo apresentado por Jane Reis (2018) quando aduz que os métodos de interpretação constitucional decorrem da forma de entender o ordenamento jurídico, os direitos fundamentais e a relação entre as funções judicial e legislativa. Isto porque há diversos pontos de divergência entre os julgadores dentro da decisão analisada, conforme demonstrou-se alhures.

Conclui-se que a jurisprudência do STF inovou em um único ponto, qual seja: ao prestigiar os princípios da segurança jurídica e da confiança legítima, definiu que, após decorrido o prazo de 5 anos, contados do ingresso do processo administrativo no Tribunal de Contas, haverá um registro tácito do ato de aposentadoria, onde tal ato será considerado definitivamente registrado.

Por fim, conclui-se que os Tribunais de Contas possuem função social relevante e evidente na apreciação da legalidade da aposentadoria em regime próprio, bem assim conclui-se a segurança jurídica como um direito fundamental basilar, sendo um fator de estabilização das relações jurídicas e sociais.

\section{REFERÊNCIAS}

ALEXY, R. Teoria dos direitos fundamentais. São Paulo: Malheiros, 2008.

BRASIL. [Constituição (1988)]. Constituição da República Federativa do Brasil de 1988. Brasília, DF: Presidente da República, [2016]. Disponível em: https://bit.ly/365sctf. Acesso em: 8 jun. 2020. 
BRASIL. Decreto-Lei $\mathrm{n}^{\circ} 4.657$, de 4 de setembro de 1942. Lei de Introdução às Normas do Direito Brasileiro. Diário Oficial da União, Rio de Janeiro, 9 set. 1942. Disponível em: https://bit.ly/366JkPo. Acesso em: 20 jun. 2020.

BRASIL. Lei $\mathrm{n}^{\circ}$ 9.784, de 29 de janeiro de 1999. Regula o processo administrativo no âmbito da Administração Pública Federal. Diário Oficial da União, Brasília, DF, $1^{\circ}$ fev. 1999. Disponível em: https://bit. ly/36b0EmC. Acesso em: 20 jun. 2020.

BRASIL. Supremo Tribunal Federal. RE $\mathbf{n}^{\mathbf{0}}$ 636553/RS. Requerente: União e João Darci Rodrigues de Oliveira. Relator: Ministro Gilmar Mendes. Brasília, DF: STF, 19 fev. 2020. Disponível em: https://bit. ly/2TRaCDR. Acesso em: 18 jun. 2020.

BRASIL. Supremo Tribunal Federal. ADI $\mathbf{n}^{0}$ 4190/RJ. Requerente: Associação dos Membros dos Tribunais de Contas do Brasil (Atricon). Relator: Ministro Gilmar Mendes. Brasília, DF: STF, 10 mar. 2010. Disponível em: https://bit.ly/2U7ct7L. Acesso em: 18 jun. 2020.

BRITTO, C. A. O regime constitucional dos tribunais de contas. Fórum, Belo Horizonte, 2001. Disponível em: https://bit.ly/2JCmBmR. Acesso em: 18 jun. 2020.

CANOTILHO, J. J. G. Direito constitucional e teoria da Constituição. Coimbra: Almedina, 2000.

CARVALHO FILHO, J. S. Manual de direito administrativo. 23. ed. Rio de Janeiro: Lumen Juris, 2010. 
DWORKIN, R. Levando os direitos a sério. São Paulo: Martins Fontes, 2002.

JUSTEN FILHO, M. Curso de direito administrativo. 8. ed. Belo Horizonte: Fórum, 2012.

MARINELA, F. Direito administrativo. 6. ed. Niterói: Impetus, 2012.

MENDES, G. F. Estado de Direito e jurisdição constitucional: 20022010. São Paulo: Saraiva, 2011.

PEREIRA, J. R. G. Interpretação constitucional e direitos fundamentais. 2. ed. São Paulo: Saraiva, 2018.

SILVA, J. A. da. Curso de direito constitucional positivo. 19. ed. São Paulo: Malheiros, 2000.

SILVA, L. V. A. S. Direitos fundamentais: conteúdo essencial, restrições e eficácia. São Paulo: Malheiros, 2009. 